\title{
A difícil arte de expor mulheres artistas*
}

\author{
Ana Paula Cavalcanti Simioni**
}

\begin{abstract}
Durante todo o ano de 2009, o Musée National d'Art Moderne, mais conhecido como Centre Georges Pompidou, abrigou uma exposição considerada, por seus curadores, radical e sem precedentes: a das obras de mulheres artistas presentes em sua coleção. O critério curatorial adotado, centrado no gênero dos criadores, ainda que incomum, não é propriamente inédito. $\mathrm{O}$ museu organizou em 1995 a exposição Féminin-Masculin: le sexe de l'art e, mais recentemente, em 2007, Wack! Art and Feminist Revolution foi realizada pelo Museum of Contemporary Art, de Los Angeles. Todavia, a dimensão de Elles a destaca e a singulariza; pois como explicita o diretor da instituição, a mostra ocorreu "numa escala jamais realizada por outro museu, reunindo mais de 200 artistas e mais de 500 obras em $8000 \mathrm{~m}^{2}$. .

É interessante notar que, em 2010, com apenas um ano de diferença, o Moma de Nova Iorque lançou o livro Modern Women (Butler e Schwartz, 2010), dedicado ao levantamento, análise e compreensão das obras de mulheres artistas em sua coleção. Ainda que a publicação não resulte de uma exposição, mas sim de
\end{abstract}

\footnotetext{
* Resenha do catálogo Elles@centrepompidou. Artistes Femmes dans La Collection du Musée National d'Art Moderne, Centre de Création Industrielle. Paris, Centre Pompidou, 2009. Agradeço a Marina Maluf que, gentilmente, presenteou-me com esse catálogo após visitar a exposição referida em Paris. Recebida para publicação em março de 2011, aceita em abril de 2011.

** Doutora em Sociologia pela USP, docente do Instituto de Estudos Brasileiros (IEB/USP). ana.simioni@hotmail.com

1 No original: "[....]D'où l'idée de leur consacrer la totalité de cette nouvelle installation de la collection, d'étender cette présentation à une échelle jamais atteinte par aucun musée, rassemblant plus de 200 artistes et plus de 500 oeuvres sur quelque $8000 \mathrm{~m}^{2} "(13)$.
}

cadernos pagu (36), janeiro-junho de 2011:375-388. 
A difícil arte de expor mulheres artistas

um projeto de pesquisa, a sincronia é reveladora. Trata-se de consistente indício do impacto que os estudos sobre as relações entre arte e gênero realizados no ambiente acadêmico foram finalmente capazes de gerar no campo das instituições artísticas. Pode-se dizer que tais debates tiveram início nos anos de 1970, com o célebre artigo de Linda Nochlin (1973), Why there been no greatest women artists, no qual a autora indagava-se sobre as causas da aparente inexistência das mulheres artistas na história. Ao demonstrar que tais lacunas em nada derivariam da ausência "natural" de talentos, mas sim da exclusão feminina das principais instâncias de formação de carreiras artísticas ao longo dos séculos XVIII e XIX - as academias de arte -, a autora ensejou um importante deslocamento explicativo, inaugurando o que se pode denominar como uma perspectiva feminista na história da arte. Desde então, inúmeras monografias, artigos e livros dedicados a mulheres artistas, bem como colóquios, revistas e debates acadêmicos passaram a mobilizar, de diversas maneiras, a dimensão do gênero, para refletir sobre as produções artísticas, sua história e os limites da historiografia da arte tradicional. ${ }^{2}$ Cabe notar que uma questão nevrálgica em tais estudos diz respeito ao modo desigual com que as instituições historicamente trataram homens e mulheres, o que significa esquadrinhar tanto aquelas instituições dedicadas à formação dos artistas, como àquelas dedicadas à consagração de sua atividade, tais como a crítica de arte, a imprensa, o mercado e, finalmente, os espaços expositivos e os museus. Assim, o fato de dois museus de notória relevância e prestígio, alocados nas duas maiores metrópoles da arte moderna do século XX - Paris e Nova Iorque - terem, quase ao mesmo tempo, produzido uma exposição e um vasto estudo sobre obras das artistas mulheres de suas coleções é, em si, uma resposta concreta e positiva às proposições, indagações e críticas que as

2 A bibliografia a esse respeito é por demais extensa para que possa ser aqui resumida. Sugiro então algumas obras de referência que sintetizam parcialmente o debate: Broude \& Garland, 1982; Pollock, 1994 a e b. 
relações entre gênero $e$ arte vêm sedimentando há algumas décadas.

Para dar corpo a tal proposta, as obras foram organizadas a partir de divisão temática, e não cronológica. Opção essa que, por sinal, é afirmada na introdução do catálogo como uma diretriz do Musée d'Art Moderne e, diferindo da questão do gênero da autoria, não é debatida com a profundidade esperada em nenhum outro momento. ${ }^{3}$ Os módulos apresentados em sua sequencia original são os seguintes: Pionnieères [Pioneiras], Feu à Volonté [Fogo livre], Corps Slogan [Corpo Slogan], Eccentric Abstraction [Abstração Excêntrica], Le Mot a l'Oeuvre [Da Palavra à obra], "Un Chambre a Soi" [Um quarto para si], Immaterielles [Imateriais] e "A Propos de l'Exposition" [Acerca da Exposição]. O catálogo que será neste texto discutido é composto por uma introdução para cada um dos módulos assinada por um curador responsável, ao que se segue um conjunto de obras escolhidas como ilustrativas da questão abordada, sem com isso se esgotar todas aquelas presentes na exposição e, ao final, uma série de 15 ensaios e documentos sucintos que permitem recuperar histórica $e$ teoricamente os debates sobre arte e gênero no campo da história da arte.

Tendo em vista a amplitude possível de temas ofertados para a reflexão pelo catálogo e pela mostra, gostaria de me dedicar particularmente a um: a escolha por expor "apenas" mulheres artistas; questão que possui centralidade nos estudos sobre arte e gênero. $\mathrm{O}$ partido adotado provoca inúmeros questionamentos que, sabiamente, os curadores não tentaram responder de modo definitivo ou tranquilizador. Elles se pretendeu mais do que uma exposição de obras selecionadas por sua suposta inquestionável qualidade artística dispostas num espaço

3 Existem vários critérios curatoriais possíveis, dentre eles os mais recorrentes são os que agrupam as obras ou autores por sua proximidade histórica, ou ainda por afinidade estilística, fazendo parte de escolas, movimentos ou grupos artísticos comuns, bem como as divisões por nações, países ou regiões, entre diversas outras possibilidades. 
A difícil arte de expor mulheres artistas

museal tendo como fim último a sua simples visibilidade. A mostra procurou suscitar um vasto programa pluridisciplinar de discussões sobre as complexas relações entre arte e gênero. Prova disso é que ao lado da exposição e do catálogo, o Museu colocou a disposição um amplo conjunto de documentos em seu site (vídeos históricos e contemporâneos, entrevistas com artistas, textos críticos, manifestos etc.), bem como estimulou debates virtuais sobre temas diversos que perpassam $e$ tangenciam a exibição. ${ }^{4} \mathrm{O}$ próprio catálogo publicado exibe constantemente a preocupação com as bases teóricas que alicerçam as escolhas, amparando $e$ sustentando o gênero como um critério possível $e$ instigante de indagação, ao mesmo tempo em que não se furta a enfrentar um evidente dilema: a fim de dar visibilidade às mulheres artistas optou-se por autonomizá-las em função de algo em comum, seu pertencimento ao mesmo "sexo" 5 , com isso não se incorre no perigo de suscitar a falaciosa crença na existência de uma sensibilidade, uma plástica, um espírito comum a todas? Ou, em outros termos, se estaria revisitando o fantasma de uma "arte feminina"?

Tamar Garb (1989) demonstrou o nascimento da categoria "arte feminina" no século XIX como um nicho particular para abrigar o que era então uma novidade: um grande contingente de artistas do sexo feminino que almejavam expor suas obras. Para tanto as associações femininas como a Union des femmes peintres et sculpteurs desempenharam um papel fundamental ao possibilitarem que as artistas expusessem seus trabalhos, o que não era de pouca importância tendo em vista as dificuldades que enfrentavam para se formarem e serem avaliadas de modo

${ }^{4}$ A exposição foi um evento catalisador de várias outras intervenções. $\mathrm{O}$ catálogo é apenas um de seus desdobramentos. O site inclui numerosos documentos, obras, debates e textos que foram postados ao longo do tempo em que exposição ficou em cartaz, portanto contendo informações que transcendem e complementam tanto a exibição quanto o catálogo dela resultante. Para maiores informações, consultar: http://elles.centrepompidou.fr

5 Sobre a complexa diferença entre sexo e gênero, consultar: Scott, 1998. 
equiparável aos homens. Todavia, esses salões exclusivos estimularam um olhar diferenciado para as suas obras, que paulatinamente passaram a ser julgadas não a partir de valores estéticos determinados pelo campo artístico, mas sim de expectativas sociais ditadas pelas demandas de seu gênero, como a de serem "doces", "femininas", "delicadas", "graciosas", etc. No limite, a "arte feminina" impôs-se então como uma modalidade classificatória perigosa na medida em que tanto solapava a diversidade estética das obras feitas por mulheres, quanto as afastava dos debates estéticos centrais.

Em La gêne du féminin, um pequeno e lúcido ensaio presente no catálogo, Élisabeth Lebovici (276-279) aborda o modo com que a categoria "arte feminina" continuou a ecoar no olhar dos críticos na França da primeira metade do século XX, fazendose perceptível nos escritos de Camille Mauclaire, Appolinaire e mesmo Aragon. O feminismo dos anos de 1970 a retoma, em um novo contexto, atribuindo-lhe sentido diverso. As ideias de Hélène Cioux podem ser vistas como emblemáticas desse momento, pois sua defesa de uma "escritura feminina" como expressão de uma subjetividade diversa daquela predominante (a masculina) recoloca a existência de um estilo comum às mulheres. Todavia, trata-se agora de uma categoria reivindicada pelos próprios sujeitos e, vale frisar, positivada.

$\mathrm{O}$ mencionado artigo, bem como o escrito por Quentin Bajac dedicado ao módulo "Feu à volonté", que inclui obras mais diretamente relacionadas ao feminismo, exploram bem a diversidade que a questão assumiu a partir da década de 1980, transcendendo (ainda que reconhecendo a relevância histórica) do discurso essencialista que prevaleceu nos anos de 1970. Nesse sentido, apresentam-se desde obras que tratam de modo militante a questão das diferenças de gênero, questionando o lugar das mulheres na história da arte, tais como as "Guerrilas Girls", bem como outras produções que abordam de modo irônico os valores estéticos dominantes, tais como Rebecca Horn, Louise Lawer, ou Rosemarie Trockel. A partir dos anos de 1980, segundo o autor, 
A difícil arte de expor mulheres artistas

cada vez mais mulheres artistas lançam seu olhar sobre a história em seu sentido mais público, destacam-se então fotógrafas como Susan Meiselas, e seu retrato dos conflitos na América Central, ou ainda Tania Bruguera e Sigalit Landau em sua busca por documentar os conflitos entre Israel e Palestina. $O$ íntimo e o político convergem nos trabalhos de Sanja Ivekovic e Sandra Vásquez de la Horra, ambas alternando suas memórias pessoais ao passado recente de seus países, os conflitos na ex-Iugoslávia e a ditadura de Pinochet no Chile, respectivamente. Como finaliza o autor, essa geração coloca-se a tarefa de debater o papel das mulheres na história contemporânea. Seja como for, percebe-se que o fardo da tradição associada à "arte feminina" ainda colocase para muitas artistas como um tema que tanto pode ser reivindicado, como criticado, parodiado, ironizado, ou negado.

Retomo então o problema: expor obras de artistas mulheres em separado é, realmente, uma boa opção? O capítulo de Camile Morineau (14-19) intitulado Elles@centrepompidou: un appel à la difference é um dos que mais diretamente enfrenta a pergunta. Segundo a autora, o gesto expositivo é propositalmente paradoxal. O museu optou por expor apenas mulheres, mas não para demonstrar que existe uma arte feminina ou um objeto feminista, mas ao contrário, para explodir as supostas unidades $e$ estereótipos. Alicerçando-se nas teorias de Joan Scott (1996), retoma-se a existência de dois universalismos contraditórios na origem do pensamento republicano francês. Primeiramente, aquele dos direitos políticos individuais, universalista, igualitário $e$ válido para aos homens (pois apenas para eles facultava-se a plena cidadania e participação política) e, por outro lado, o universalismo da diferença sexual, considerada como diferença "natural" entre homens e mulheres, a qual subsidiaria expectativas de atuações sociais diversas para cada sexo. Como defendeu a autora, na história contemporânea da França o universalismo da diferença prevaleceu sobre o dos direitos naturais, a ponto do indivíduo abstrato não ser neutro, mas masculino. A desnaturalização de tal sujeito passa, necessariamente, pelo 
reconhecimento de que existe um "outro" não representado nessa categoria, esse outro oculto e silenciado que são as mulheres. $\mathrm{O}$ desmascaramento da masculinidade sub-reptícia implícita no sujeito universal iluminista exige que se reivindique o lugar da "diferença" da categoria mulheres, diferença essa que, ironicamente, foi a base sobre a qual se erigiu todo um sistema de desigualdades sociais.

Nesse sentido, a exposição é atravessada por um duplo e profundo paradoxo, como todo gesto que tenta interrogar, retificar ou simplesmente evocar uma paridade não resolvida. De um lado, $\mathrm{o}$ ato que impede as mulheres de tomar a palavra; de outro, aquele que as impede de a tomarem a não ser em nome das mulheres. Assim, a conclusão de Scott é reivindicada por Morineau como legitimadora dos partidos curatoriais tomados: a fim de almejar o universalismo, é preciso paradoxalmente tomar a palavra, para tanto fazendo-o em nome da diferença das mulheres, a mesma que, num primeiro momento, as conduziu à exclusão. É justamente essa a contradição de reivindicar a particularidade com vistas a promover a visibilidade das artistas, a multiplicidade de suas potencialidades, suscitando uma autocrítica dos atores e instituições, que permitirá um objetivo ainda maior, o de promover uma outra história da arte possível. Trata-se de finalmente dar a "elles" a palavra, por meio de um gesto ambíguo no qual a diferenciação pelo gênero existe apenas para abrir-se para a universalidade, a mistura e a excelência; no limite, para explodir a própria unidade contida na ideia da diferença que supostamente as uniria (17).

$O$ texto de Morineau exibe, de modo muito bem fundamentado teoricamente, as justificativas das escolhas curatoriais. Todavia, quando examinamos as subdivisões em módulos tais como se nos apresentam pelo catálogo, novas interrogações despontam, sendo estas sugestivas muito mais da dificuldade de encontrar critérios coerentes teoricamente $e$ artisticamente para congregar obras do que de qualquer tipo de ausência de capacidades da parte dos seus idealizadores. No 
A difícil arte de expor mulheres artistas

limite, a exposição pode também ser tomada como um exemplo instigante das muitas dificuldades contidas nas escolhas $e$ atividades dos curadores.

O primeiro dos módulos intitula-se Pionnières [Pioneiras]. Congrega a produção de artistas pertencentes ao círculo das vanguardas desde finais do século XIX até os movimentos mais tardios, como o surrealismo das décadas de 1930 e 1940. Tais mulheres enfrentaram um desafio comum: o de lidarem de modo complexo $e$ inventivo com os estereótipos $e$ preconceitos tradicionais que se abatiam sobre a arte feita por mulheres em suas épocas. Casos como os de Suzanne Valadon, Marie Blanchard e Marie Laurencin são paradigmáticos das possibilidades de ingresso no mundo artístico inauguradas com os circuitos modernistas das quais todas fizeram, ativamente, parte. Mas suas inserções foram pautadas pelo signo da ambiguidade. $\mathrm{O}$ modo com que Appollinaire julgou Marie Laurencin como uma típica representante de uma arte moderna "feminina" é esclarecedor; exemplifica uma tendência interpretativa geral que prevalecia na primeira metade do século $\mathrm{XX}$ mesmo no interior dos circuitos modernistas. ${ }^{6}$

O texto de apresentação do módulo, assinado por Cécile Debray, explicita que tais artistas enfrentaram, criativamente, o peso da herança identitária que sobre elas pesava. Tanto a herança de gênero, tantas vezes presente nas obras de cunho criticamente autobiográfico como as de Frida Kahlo ou Hannha Höch, quanto o modo com que o gênero associou-se a outra herança, a das tradições culturais não-eurocêntricas - questão evidente nas incorporações de padrões iconográficos e artesanais levados a cabo Natalia Goncharova e, novamente, Frida Kahlo. Vale notar que no texto de Debray, bem como no sucinto e muito

${ }^{6}$ Como aponta Cécile Debray (26), Laurencin é abordada pela historiografia como uma "musa" de sua geração, e não como uma pintora plena. Para tanto, os textos de Appolinnaire tiveram papel fundamental ao se referirem a ela como "graciosa", bem como alguém que se situa entre Picasso e Douanier Rousseau, ou seja, sem uma independência artística absoluta. 
sugestivo ensaio assinado por Patrick Favardin (248-249) sobre as mulheres e o design, a maneira com que as artistas lograram revolucionar os estereótipos de gênero que rondavam tanto as tradições artesanais quanto elementos da cultura material atrelados a uma feminilidade desvalorizada, é um mote precioso. Lembremos aí da transformação que Sonia Delaunay imprimiu às artes têxteis, antes vistas como "naturalmente" domésticas, artesanais e femininas, ou seja, inferiores, e que, depois de sua aplicação particular do orfismo às estamparias, tapetes e à moda, tornaram-se emblemáticas de um modo de ser moderno.

Também os casos Charlotte Perriand e Janette Laverrière são muito sugestivos. Ambas pertenceram aos mais afamados círculos de vanguarda de seu tempo e obtiveram sucesso em suas carreiras por se notabilizarem como produtoras de linguagens extremamente modernas no interior de práticas até então negligenciadas, porque feminilizadas, como a decoração de interiores. Para compreender as trajetórias, Favarday lança mão de uma perspectiva analítica fecunda, presente também no artigo de Debray, que é a de entender o ingresso das artistas nos circuitos de vanguarda por meio da interação estabelecida com os colegas homens, ou seja, pelos vínculos de parceria diversos que lograram constituir. Tal visada permite compreender a particularidade das trajetórias e obras, percebidas em sua materialidade, sem as autonomizar excessivamente. Obras $e$ artistas mulheres são vistas em sua relação com a de outros artistas com quem dialogavam, tanto em suas vidas cotidianas, quanto em seus trabalhos. Tal tipo de análise contextualiza o modo com que a dimensão do gênero pesava concretamente sobre as artistas, traduzindo-se em estilos, modalidades e práticas que lhes eram então "destinadas", tais como as artes decorativas, aplicadas - em uma expressão, as artes vistas como "domésticas". No entanto, como o texto permite ver, as determinações não eram absolutas ou intransponíveis: tais pioneiras destacaram-se pela forma com que subverteram tal legado, logrando construir carreiras bem sucedidas em campos até então ora compreendidos 
A difícil arte de expor mulheres artistas

como masculinos, ora subvalorizados por serem femininos. Suas atuações foram fundamentais na promoção da própria reavaliação da importância de tais modalidades, conferindo-lhes um novo lugar na história da arte. ${ }^{7}$

A indagação consciente e política do lugar das mulheres na história da arte que caracteriza a produção feminista em vigor nos anos 1970 e 1980 é o mote do segundo módulo do catálogo, Feu a Volonté. Nele encontram-se reproduzidas obras de Orlan, Judy Chicago, Betty Tompkins, Rosemaire Trockel, Chantal Akerman, Niki de Saint Phale, etc. Para além da inegável qualidade das obras e das artistas representadas, o que as une? Quando se observa suas produções percebe-se que para algumas a crítica à sociedade "patriarcal" passa pela tematização do corpo feminino e da afirmação de sua força sexual, como, por exemplo, na obra de Orlan, "Baiser de l'artiste", que em seu contexto, 1975, era transgressora; ou ainda nas obras propositalmente eróticas de Judy Chicago, Betty Tompkins e Hannah Wilke. Mas há dúvidas sobre o porque dessas artistas terem sido inseridas nesse módulo e não no seguinte, Corps Slogan. Este é dedicado justamente à forma com que o corpo consiste em um mote privilegiado da pesquisa e criação estética para diversas mulheres, visível especialmente no espaço que as performances ocupam em seus trabalhos.

Outras artistas escolhidas como representativas do módulo Feu à Volonté no catálogo incorporam o feminismo por meio de um debate sobre a feminilização dos meios artísticos, tais como Rosemaire Trockel que, em sua leitura crítica do legado da abstração racionalista de Malevitch, compõe obras em faturas tradicionalmente vistas como "femininas', como os tecidos e os bordados. E novamente pergunto-me, por que está nesse módulo e não em Eccentric Abstracion? - espaço no qual o tema geral é

7 Nesse ponto há uma lacuna incompreensível a se considerar tanto no catálogo quanto no acervo do Museu: o das mulheres artistas da Bauhaus. A esse respeito, consultar: Weltge, 1993. 
justamente a forma com que diversas artistas questionaram $e$ subverteram a teoria modernista, paradigma dominante na história da arte contemporânea, que em sua defesa da evolução artística rumo à simplificação das formas, e da busca de uma essência (conceitual?) tendeu a sub-valorizar práticas, estilos e plásticas associadas às dos "outros", como as mulheres, os artistas naif, ou as "artes primitivas". O ornamento, a decoração, a cor, a materialidade artesanal, tudo aquilo que, grosso modo, Camile Morineau, autora do texto dedicado a esse módulo denomina como "arte orgânica", tornou-se uma espécie de excrescência nesse trajeto da arte contemporânea rumo à uma pureza estrutural. Nas mãos de tais artistas, tais "sobras" ou "desvios" tornam-se matéria constitutiva, predominante. Ao trazerem para o centro aqueles elementos que estavam à margem, elas subvertem o discurso, colocam em xeque sua unicidade, sua supremacia. A escolha de artistas como Valérie Jouve, Hanne Darboven, Ghada Amer, entre outras, é plenamente satisfatória, as obras convincentes. O problema é entender porque algumas artistas estão nesse módulo e não em outro. Por vezes, o catálogo enseja a sensação de que a proposta teórica, apesar de lúcida $e$ consistente, bem como as obras, de inegável qualidade, não se combinam. Ou seja, o discurso, apesar de interessante, não encontra apoio nas materialidade das obras que ali se exibem.

Esse problema permanece em outros espaços abordados no catálogo. O que diferencia, formalmente, as obras reproduzidas no módulo Le mot a l'oeuvre - dedicado à problemática da arte conceitual, entendida como uma pesquisa consciente da questão da linguagem artística, um dos momentos da história de desmaterialização da obra de arte característica de parte da produção da segunda metade do século XX - do módulo seguinte, Immaterielles, que o próprio título indica tratar-se da problemática da desmaterialização? No primeiro caso, o catálogo esclarece, existira uma preocupação (especificamente feminina?) com o questionamento sobre a linguagem enquanto discurso, sobre o "eu" que emite a palavra; enquanto que no segundo caso haveria 
A difícil arte de expor mulheres artistas

uma reivindicação da plena autonomia do artista, sendo a questão do gênero superada por um novo tipo de sensação de universalidade. Se no discurso tal diferenciação parece convincente, quando olhamos as obras que o catálogo apresenta como representativas, as diferenças, os critérios, tornam-se bem menos visíveis. Só para dar alguns exemplos, Nan Goldin com sua instalação "Heartbeat" parece tematizar muito mais a questão da sexualidade e da identidade sexual, própria a outros módulos que não a questão conceitual ${ }^{8}$; Gina Pane com a exposição de "Action Autoportrait(s): mise en condition, contraction, rejet" bem poderia estar em Feu à Volonté $e^{9}$ : Marine Aballéa com seu trabalho sobre o gênero dos objetos exibido em "The Memory Club" ficaria bem melhor no módulo "Un chambre a soi", dedicado à tematização da relação entre o espaço $e$ as mulheres, do que entre artistas conceituais.

Enfim, apesar de textos, obras, artistas e objetivos serem excelentes, por vezes parecem disparatados. A opção temática, e não histórica, que ordena os módulos pode ser sugestiva à reflexão, mas talvez não o seja para uma vista à exposição, ou seja, produz debates instigantes e fundamentados intelectualmente, mas padece justamente de seu intelectualismo. As obras apresentadas como ilustrativas dos textos nos catálogos nem sempre correspondem ao que delas é exigido. E não porque elas não são capazes de comunicar, porque não provoquem, mas porque os critérios curatoriais parecem corresponder por vezes

\footnotetext{
8 A obra projeta 245 fotografias coloridas, nas quais duplas compostas por mulheres-homens, homens-homens, mulheres-mulheres são captadas em cenas sexuais, ao fundo escuta-se a canção "Prayer of The Heart". Ver catálogo, p. 192.

9 Nessa obra de 1973, a artista registra uma performance dedicada a "transposer l'auatocréation em signe autonome de la femme", para tanto recupera atividades pulsionais que sobre elas pesam no nível do espírito e da matéria: dor, fantasmas, contradições, rejeição, são modos de provocar "la desctruction de quelque chose pour la mise au jour d'um nouveau langage: celu de la FEMME" [....], verElles@centrepompidou,pp.202-203.
} 
mais a escolhas teóricas prévias do que aquelas suscitadas pelas próprias obras e artistas.

Expor as obras de artistas mulheres, por tanto tempo negligenciadas pelas instituições, é uma real contribuição para a revisão da historiografia da arte dominante, mostrando um notável avanço das instituições. Fomentar a discussão pública sobre tais temas, bem como gerar um catálogo com textos de alto calibre é também uma postura muito bem vinda, contribuindo para o adensamento do campo de pesquisas e reflexões em história da arte na contemporaneidade, algo que poderia ser replicado em outros eventos semelhantes, inclusive no Brasil. Mas Elles não veio para aplacar o leitor, e sim para inquietá-lo. Assim, as dúvidas sobre as opções delineadas pelos partidos curatoriais debatidos no catálogo produzido a partir da exposição podem permanecer, ser alvo de novos questionamentos. Organizar as artistas apenas em função do gênero é de fato um critério que subsiste às décadas de uma história da arte compromissada com a crítica da separação entre os gêneros, que tanto tem insistido em sua dimensão "relacional"? Não teria sido também oportuna uma reflexão sobre as políticas de aquisição institucionais a partir da década de 1960? Quais são, afinal, os critérios que guiaram a constituição dos acervos e, portanto, que permitiram a formação desse conjunto notável mobilizado pela exposição e reproduzido em seu catálogo, mas ainda assim sujeito a ausências de outras artistas? Questões essas suscitadas a partir do debate possibilitado por esse evento complexo e corajoso que se intitulou "Elles", que já nasceu como um marco e permanecerá por meio das reflexões que é capaz mobilizar.

\section{Referências bibliográficas}

BROUdE, Norma \& GARLAND, Judith. Feminism and Art History. Questioning the Litany. New York, Harper \& Row Publishers, 1982. 
A difícil arte de expor mulheres artistas

ButLER, Cornelia and SCHWARTZ, Alexandra. (orgs.) Modern Women. Women Artists at the Museum of Modern Art. New York, Moma, 2010.

GARB, Tamar. L'Art Féminin: The Formation of a Critical Category in Late Nineteenth-Century France. Art History, London, vol. 12, ${ }^{\circ} 1$, mar 1989, pp.39-65.

Nochlin, Linda. Why There Have Been no Gratests Women Artists? Art and Sexual Politics. New York, Macmilan Publishing Co, 1973, $2^{\text {a }}$ ed.

POLLOCK, Griselda. Vision and Difference. Feminity, Feminism and the Histories of Art. London, Routledge, 1994a.

POLLOCK, Griselda. Histoire et politique: l'histoire peut-elle survivre au feminism?. Féminism, Art et Histoire de l'Art. Paris, Esnba, 1994b.

SCOTT, Joan. Genre: une catégorie utile d'analyse historique. Les Cahiers du Grif, Paris, n 37/38, 1998.

ScOTT, Joan. Only Paradosex to Offer. French Feminism and the Rights of Man. Harvard University Press, 1996.

WeltGe, Sigrid Wortmann. Women's Work. Textile Art From the Bauhaus. London, Thames and Hudson, 1993. 